\title{
HACIA UN ESTADO DE LA CUESTIÓN SOBRE TEATRO Y NUEVAS TECNOLOGÍAS EN ESPAÑ ${ }^{1}$
}

\author{
José ROMERA CASTILLO \\ Universidad Nacional de Educación a Distancia \\ jromera@flog.uned.es
}

Resumen: El propósito de este estudio es examinar las aportaciones bibliográficas de lo investigado y publicado en España, en castellano solamente, sobre la relación del teatro y las nuevas tecnologías, dejando a un lado lo referente a la creación dramatúrgica en sí misma (portales de autores y obras, puestas en escena, bibliotecas, mundo editorial, revistas electrónicas, etc.). El estudio se centra en unos cuantos ejemplos de los volúmenes individuales o colectivos que han versado sobre el tema.

Abstract: The purpose of this study is to examine the bibliographical contributions of the investigated and published in Spain (in Spanish language only) on the relation between theatre and new technologies, leaving aside all references on drama creation (authors' portals and works, staging, libraries,

\footnotetext{
${ }^{1}$ Este trabajo se inserta en el Proyecto de Investigación HUM2006-02641 (2006-2009), dirigido por mí, otorgado por el Ministerio de Educación y Ciencia.
} 
publishing, electronic magazines, etc.). The study is based on a few examples of the individual or collective volumes that have turned on the topic.

Palabras clave: Teatro Español. Nuevas Tecnologías. Bibliografía sobre Teatro.

Key Words: Spanish Theatre. New Tecnologies. Bibliography on Theatre

\section{PREÁMBULO}

Me complace participar en esta parte monográfica de la revista Signa, coordinada por Dolores Romero López, dentro de las actividades del Centro de Investigación de Semiótica Literaria, Teatral y Nuevas Tecnologías de la UNED, que dirijo (como puede verse en $h t t p: / / w w w$-uned.es/centro-investigacion-SELITEN@T). Los estudios aquí compilados, además de sumarse a otros de los publicados en España (que, por otra parte, no son muchos: eso hay que constatarlo de inmediato), serán cauce de investigaciones fructíferas que servirán - qué duda cabe - a la difusión, nacional e internacional, de la utilidad que proporcionan nuevas herramientas en la creación, la difusión y el estudio del espectáculo teatral.

Antes de entrar en la materia que me ocupa, quisiera delimitar el radio de acción de mis objetivos. En primer lugar, mi pretensión no es otra que la de examinar algunos botones de muestra de lo investigado y publicado en España, en castellano solamente, sobre la relación del teatro y las nuevas tecnologías, dejando a un lado lo referente a la creación dramatúrgica en sí misma (portales de autores y obras, puestas en escena, bibliotecas, mundo editorial, revistas electrónicas, etc.). No pretendo, pues, hacer un estado de la cuestión (exhaustivo) de los estudios, sino que como queda fijado en el título, me centraré en unos cuantos ejemplos (significativos, creo) de los volúmenes individuales o colectivos, fundamentalmente (dejando para otros o para otra ocasión el estudio pormenorizado de los artículos, publicados en revistas y otros lugares, que, sin duda, son mucho más numerosos), que han versado sobre el tema.

Asimismo, quisiera dejar muy claro - para evitar suspicacias diversas que no tendré en cuenta en esta mi ejemplificación lo publicado en otras lenguas del Estado español (catalán, gallego o vasco) sin ánimo alguno de discriminación, sino que se debe tanto a mi especialización profesional (inves- 
tigador del teatro en español) como a un cierto desconocimiento global de lo publicado en esas lenguas sobre el tema, por lo que invito a otros investigadores de esos ámbitos linguiísticos a añadir lo que aquí no se tenga en cuenta. Tampoco acudiré a publicaciones aparecidas en otras áreas lingüísticas del español (Iberoamérica está empujando con fuerza en este terreno); ni a las traducciones a la lengua de Cervantes (que bien merecen un estudio aparte); así como no citaré ninguna bibliografía escrita en otra lengua que no sea la española.

Delimitado el campo, se puede intuir fácilmente que, desde un planteamiento general de las relaciones del teatro (su estudio y difusión) con las nuevas tecnologías, mi propósito no es otro que el de hacer unas calas, y, por ende, algunas reflexiones, para examinar algunas aportaciones que hemos realizado en estos últimos años, estando avocado este trabajo a refrescar la memoria de algunos y a contentar a los menos iniciados en el tema.

Como es bien sabido, a lo largo de la historia han sido tres las grandes revoluciones que han dejado huella en las manifestaciones humanas, en general, y en las artes (dentro de las cuales se inserta la literatura y el teatro), en particular: la primera, se manifiesta a través del paso de la oralidad a la escritura; la segunda, llegó con la invención de la imprenta, en 1492; y la tercera, ha venido con el advenimiento no hace muchos años todavía de las nuevas tecnologías, o dicho de otro modo, de lo digital y cibernético. Hemos pasado en la nueva era que vivimos del bisonte a la realidad virtual o, si se prefiere, del homo sapiens al homo digitalis.

No voy a entrar en la variada bibliografía generada sobre las relaciones entre la literatura, en general, y las nuevas tecnologías en España en estos últimos años (Romera Castillo et alii, eds., 1997: 13-82)²; como también expuse en el estado de la cuestión que realicé en mi intervención, en la sesión plenaria «Investigación y difusión de la literatura y el teatro en la red: algunos ejemplos de lo publicado en castellano en España», en el Congreso $L i$ teraturas: del texto al hipertexto, celebrado en la Universidad Complutense (Madrid, 21-22 de septiembre de 2006) - al que remito-, cuyas Actas están en prensa.

Constataré que la escritura dramática - el texto escrito-, al pertenecer de lleno al ámbito literario, como otros elementos sígnicos que intervienen en lo

\footnotetext{
${ }^{2}$ Indicaré que para las notas no sigo el sistema anglosajón, con el fin, al referirme a artículos publicados en revistas, fundamentalmente, de cumplir mi objetivo — analizar solamente libros - y no abultar en demasía las referencias bibliográficas finales.
} 
espectacular - en la representación teatral-, se han visto, se ven y, sobre todo, se verán afectados por estos nuevos instrumentos mediáticos.

\section{EL CENTRO DE INVESTIGACIÓN DE SEMIÓTICA LITERARIA, TEATRAL Y NUEVAS TECNOLOGÍAS}

Nuestro Centro de Investigación, como se anuncia en su denominación, no ha sido ajeno al impulso del estudio de la literatura y el teatro y su relación con las nuevas tecnologías. Aunque son varias las líneas de investigación que se llevan a cabo en su seno, una de ellas se ha centrado en el estudio del tema. Y hablo en plural, porque el conjunto de sus logros pertenece a un grupo de investigadores, que, bajo mi coordinación, trabajamos en equipo (que, por otra parte, es la forma mejor de investigar, según mi criterio).

Como el interés por el estudio de las relaciones de lo teatral y las nuevas tecnologías no tenía parangón con el del espacio literario, consideré que era necesario y conveniente dedicar una sección monográfica de uno de nuestros Seminarios Internacionales a este novedoso tema, que en España no había sido tratado con anterioridad con la extensión y profundidad debidas. Nuestro Centro de Investigación, por tanto, una vez más, se convertía en pionero en este ámbito, al dedicar a su estudio el XIII Seminario Internacional, celebrado conjuntamente en la UNED y Casa de América (Madrid), del 25 al 27 de junio de 2003, posteriormente editado por José Romera Castillo (2004), Teatro, prensa y nuevas tecnologías (1990-2003)³.

La primera parte del Seminario versó sobre la prensa y el teatro; mientras que la segunda, se dedicó al estudio de las relaciones del teatro con las nuevas tecnologías en el espacio cronológico marcado. En esta parte hay que destacar, ante todo, las reflexiones de Jesús Campos (dramaturgo y Presidente de la Asociación de Autores de Teatro), «Naufragar en Internet. La tecnología como metáfora» (35-41) - no podían estar ausentes los creadores textuales en nuestro encuentro-, que reflexiona sobre estas nuevas herramientas, disponibles para el ser humano, con su utilidad y sus prevenciones.

\footnotetext{
${ }^{3}$ Con reseñas de Mar Rebollo Calzada, en Las Puertas del Drama 19 (2004), 36-38; Irene Aragón González, en Epos XX/XXI (2004-2005), 481-483; Francisco Gullón de Haro, en Signa 14 (2005), 401-405 (también en http://cervantesvirtual.com/hemeroteca/signa/) y Petra García Cerro, en Anales de la Literatura Española Contemporánea 31.2 (2006), 313 / 699-317 / 703. Cf. además el trabajo de José Romera Castillo (2006), «Sobre teatro, prensa y nuevas tecnologías».
} 
En segundo lugar, hay también unos postulados teóricos de José M. ${ }^{a}$ Paz Gago (Universidade da Coruña), sobre «Ciberteatro. Teatro y tecnologías digitales» $(81-88)^{4}$. Al igual que se publica en el volumen el trabajo genérico y de gran interés de Francisca Martínez González (Universidad de Alicante), sobre los «Proyectos teatrales en la Biblioteca Virtual Miguel de Cervantes» (59-71), «un fondo bibliográfico y documental que, mediante la utilización de las nuevas tecnologías, se pone libremente a disposición de los usuarios de Internet con el objetivo de difundir las obras y los documentos más destacados de la cultura».

En tercer lugar, aparecen en el volumen unas propuestas como las que hacen Monique Martinez (Université de Toulouse-Le Mirail) y Sandra Golopentia (Brown University), quienes en «El tratamiento informático de la dirección escénica ¿una práctica transgresiva?» (73-79) exponen el diseño de «un programa informático que serviría tanto para un análisis dramatúrgico particular, previo a la puesta en escena, como para la notación de las propias didascalias del autor»; así como la de Víctor Manuel Peláez Pérez (Universidad de Alicante), que propone unos «Aspectos metodológicos de la edición virtual de la parodia dramática» (433-442). Por su parte, varios integrantes de nuestro equipo de investigación estudian otras variantes del tema: Alicia Molero de la Iglesia (SELITEN@T) se fija en «Los contenidos teatrales en la edición electrónica» (399-411) y Sonia Núñez Puente (SELITEN@T) analiza el «Teatro español en Internet: directores, compañías y actores» (413-432). Asimismo, Manuel Pérez Jiménez (Universidad de Alcalá), en «Panorama de las publicaciones periódicas de investigación teatral desde 1990» (103-121), aporta una serie de direcciones electrónicas de las mismas.

En cuarto lugar, hay trabajos que se fijan en la creación y puestas en escena teatrales, relacionadas con las nuevas tecnologías. Dos de ellos inciden en un ejemplo prototípico, el espectáculo de un significativo grupo catalán: Catalina Buezo Canalejo (Universidad Europea de Madrid), en «La Fura del Baus, un teatro fáustico y un Fausto del teatro: F@usto versión 3.0» (333343) y Martí Martorell Fiol (Universitat de les Illes Balears), en «La incursión en el mundo digital de La Fura dels Baus» (387-397). Asimismo, Íñigo Sarriugarte Gómez (Universidad del País Vasco), en «Interferencias entre el teatro y el performance bajo la tutela de las nuevas tecnologías» (465-473), analiza las complejas relaciones entre estas modalidades de espectáculo y las nuevas herramientas.

${ }^{4}$ Cf. además otro de sus trabajos, «Artes del espectáculo y nuevas tecnologías» (Revista DeSignis, 2006). 
El teatro foráneo en la red también está presente en los trabajos de Raquel Gutiérrez Estupiñán (Universidad Autónoma de Puebla, México-SELITEN@T), «Sabina Berman en Internet» (363-372)», que centra su atención en la dramaturga mexicana, y Marina Sanfilippo (SELITEN@T), que examina el «Teatro italiano en Internet» (455-464) ${ }^{5}$.

Constataré, además, que en algunas de las Actas de otros Seminarios Internacionales hemos tratado el tema. Así, en Literatura y multimedia (Romera et alii, eds., 1997) se inserta el trabajo, dedicado al teatro, de María del Carmen Simón Palmer, «Teatro del Siglo de Oro en CD-ROM» (319-327) - una prueba muy significativa del escaso eco que estas nuevas tecnologías tenían en el estudio del arte de Talía, desde esta perspectiva, en España, por aquellos años-; así como en las Actas del XV Seminario Internacional, Tendencias escénicas al inicio del siglo XXI (Romera Castillo, ed., 2006), aparece un interesante trabajo de Ana García Martínez, «La "red" y el teatro: Mutation-\#02 Vuelvo enseguida / We'll be rigth back, y 24/7 de Yoalanda Pallín, José Ramón Fernández y Javier G. Yague» (163-183), en el que reflexiona sobre el término «red» como metáfora de interpretación para el análisis de las obras dramáticas, en tres niveles diferentes (proceso de creación artística, plasmación temática y composición estructural), ejemplificando el marco teórico con dos piezas teatrales. Asimismo, en nuestro entorno hemos publicado el volumen de Ricardo Serrano Deza (2001), Manual de análisis infoasistido de textos aplicado al teatro de los Siglos de Oro ${ }^{6}$.

Nuestro Centro, con el fin de difundir lo realizado sobre el asunto que nos ocupa, en la entrada del menú «Estudios sobre teatro» (http://www.uned.es/centro-investigacion-SELITEN@T/ estudios_sobre_teatro.html) pone a disposición de los investigadores - además de los índices de sus Actas ${ }^{7}$, la publicación de textos tea-

\footnotetext{
${ }^{5}$ Además hay dos investigaciones que reflexionan sobre la relación del teatro con otro medio de comunicación (la radio): la de Antonio Tordera Sáez (Universidad de Valencia), «Una vieja / nueva tecnología: el escenario radiofónico» (143-157) y la de Francisco Gutiérrez Carbajo (SELITEN@T), «Teatro, radio y nuevas tecnologías (Adaptaciones teatrales y premios de teatro Ojo crítico [de Radio Nacional de España] de 1990 a 2003)» (43-57). Otros dos trabajos se fijan en las relaciones del teatro con otro medio artístico (el cinematográfico) y las nuevas tecnologías: el de Patricia Trapero Llobera (Universitat de Les Illes Balears), «Cine de animación: los nuevos titiriteros» (159-175) y el de Verónica Fernández Peebles (Universidade da Coruña), «William Shakespeare según Al Pacino» (353-361).

${ }^{6}$ Con reseña de Irene Aragón González, en Signa 11 (2002), 341-344 (también en http://cervantesvirtual.com/hemeroteca/signa).

7 Reseño solamente las relacionadas con el teatro: José Romera Castillo y F. Gutiérrez (eds.), Teatro histórico (1975-1998): textos y representaciones (Madrid: Visor Libros, 1999); José Romera Castillo (ed.), Del teatro al cine y la televisión en la segunda mitad del siglo XX (Madrid: Visor Libros, 2002), Teatro y memoria en la segunda mitad del siglo XX (Madrid: Visor Libros, 2003), Teatro, prensa y nuevas tecno-
} 
$\operatorname{trales}^{8}$ y de la revista Signa $^{9}$ - la mayoría de las carteleras y las tesis de doctorado completas, dirigidas por mí - casi todas ellas - o por otros miembros del Centro de Investigación. Un conjunto homogéneo y amplio de estudios que reconstruyen la vida escénica tanto en España como fuera de ella.

Sobre la segunda mitad del siglo XIX, figuran los trabajos de Inmaculada Benito Argáiz, La vida escénica en Logroño (1850-1900) (2003) ${ }^{10}$; José Antonio Bernaldo de Quirós, El teatro y actividades afines en Ávila (siglos XVII, XVIII y XIX) (1993) ${ }^{11}$; Emilia Cortés Ibáñez, El teatro en Albacete en la segunda mitad del siglo XIX (1991) ${ }^{12}$; Estefanía Fernández García, León y su actividad escénica en la segunda mitad del siglo XIX (1997) ${ }^{13}$; María del Mar López Cabrera, El teatro en Las Palmas de Gran Canaria (1853-1900) (1995) ${ }^{14}$; Eva Ocampo Vigo, Las representaciones escénicas en Ferrol:

logías (1990-2003) (Madrid: Visor Libros, 2004), Dramaturgias femeninas en la segunda mitad del siglo XX: espacio y tiempo (Madrid: Visor Libros, 2005), Tendencias escénicas al inicio del siglo XXI (Madrid: Visor Libros, 2006) y Análisis de espectáculos teatrales (2000-2006) (Madrid: Visor Libros, 2007).

${ }^{8}$ Cf. José M. ${ }^{a}$ Rodríguez Méndez, Reconquista (Guiñol histórico) y La Chispa (Aguafuerte dramático madrileño) (Madrid: UNED, 1999); Jerónimo López Mozo, Combate de ciegos. Yo, maldita india... (Dos obras de teatro) (Madrid: UNED, 2000); José Luis Alonso de Santos, Mis versiones de Plauto. 'Anfitrión', 'La dulce Cásina' y 'Miles gloriosus' (Madrid: UNED, 2002); Íñigo Ramírez de Haro, Tu arma contra la celulitis rebelde, Historia de un triunfador, Negro contra blanca (Tres obras de teatro) (Madrid: UNED, 2005) - todas con prólogo de José Romera Castillo (que aparecen en nuestra página electrónica) - y Juan Mayorga, Cartas de amor a Stalin, Signa 9 (2000), págs. 211-255 (también en http://cervantesvirtual.com/hemeroteca/signa). En el número 16 (2007) de Signa se incluyen textos de Pilar Campos, Selección natural (167-193) y Gracia Morales, Un horizonte amarillo en los ojos (195-219) (http://cervantesvirtual.com/hemeroteca/signa).

${ }^{9}$ La revista ha prestado atención al tema, tanto en las dos secciones monográficas de Signa 12 (2003), coordinada por José Romera Castillo, «En torno a la semiótica teatral: sobre algunas compañías profesionales en diversas ciudades españolas» (también en http://cervantesvirtual.com/hemeroteca/signa), como en Signa 15 (2006), sobre Puestas en escena de nuestro teatro áureo en algunas ciudades españolas durante los siglos XIX y XX, bajo la coordinación de Irene Aragón González (cf. José Romera Castillo, 2004).

${ }_{10}$ Parte de ella, dedicada al estudio de los espacios teatrales, ha sido publicada como De Teatro Principal a Teatro Betrón de los Herreros (Logroño: Instituto de Estudios Riojanos / Ayuntamiento de Logroño, 2006).

${ }^{11}$ Publicada en microforma por la UNED en 1994 y posteriormente como Teatro y actividades afines en la ciudad de Ávila (Siglos XVII, XVIII y XIX) (Ávila: Diputación Provincial / Institución Gran Duque de Alba, 1998; con prólogo de José Romera Castillo). Cf. la reseña de Vicente Javier de Castro Llorente, en Signa 8 (1999), 355-357 (también en http://cervantesvirtual.com/hemeroteca/signa).

${ }_{12}$ Publicada en microforma por la UNED en 1991 y posteriormente como El teatro en Albacete en la segunda mitad del siglo XIX (Albacete: Diputación / Instituto de Estudios Albacetenses, 1999; con prólogo de José Romera Castillo). Cf. la reseña de Francisco Linares Valcárcel, en Signa 9 (2000), 627-631 (también en http://cervantesvirtual.com/hemeroteca/signa/).

${ }^{13}$ Publicada en microforma por la UNED en 1998 y posteriormente como El teatro en León en la segunda mitad del siglo XIX (León: Universidad, 2000; con prólogo de José Romera Castillo).

${ }^{14}$ Publicada en microforma por la UNED en 1995 y posteriormente con igual título (Madrid: Fundación Universitaria Española, 2003). 
1879-1915 (2001) ${ }^{15}$; Tomás Ruibal Outes, La vida escénica en Pontevedra en la segunda mitad del siglo XIX (1997) ${ }^{16}$; Ángel Suárez Muñoz, La vida escénica en Badajoz 1860-1886 (1994) ${ }^{17}$ y Agustina Torres Lara, La escena toledana en la segunda mitad del siglo XIX (1996), inédita hasta el momento ${ }^{18}$.

Sobre el siglo XX -además del trabajo de Eva Ocampo Vigo sobre Ferrol - , figuran las tesis de doctorado de Paulino Aparicio Moreno, La vida escénica en Pontevedra: 1901-1924 (2000) ${ }^{19}$; Alfredo Cerda Muños, La actividad escénica en Guadalajara (México) 1920-1990 (1999) ${ }^{20}$; Coral García Rodríguez, La vida escénica del teatro español del siglo XX en Italia (19601998) (2000) ${ }^{21}$; Francisco Linares Valcárcel, La vida escénica en Albacete (1901-1923) (1997)22; Emilia Ochando Madrigal, El teatro en Albacete (1924-1936) (1998) 23; Francisco Reus-Boyd-Swan, El teatro en Alicante (1900-1910) (1991) 24; Ana Vázquez Honrubia, Teatro, cine y otros espectáculos en Llanes (Asturias): 1923-1938 (2004) ${ }^{25}$; Paloma González-Blanch

15 Publicada con igual título (Madrid: UNED, 2002; con prólogo de José Romera Castillo).

16 Publicada en microforma por la UNED en 1998 y posteriormente con igual título (Madrid: Fundación Universitaria Española, 2003; con prólogo de José Romera Castillo).

17 Publicada en microforma por la UNED en 1995 y posteriormente como El teatro en Badajoz: 1860-1886. Cartelera y estudio (Madrid: Támesis, 1997).

${ }_{18}$ De algunas de ellas se han hecho estudios conjuntos, como el de nuestra colaboradora Dolores Romero López, Bases de datos de representaciones teatrales en algunos lugares de España (1850-1900), en «Publicaciones electrónicas» (http://www.liceus.com) y en «Estudios sobre teatro» de nuestra página electrónica (http://www.uned.es/centro-investigacion-SELITEN@T/estudios_sobre_teatro.html), que ha tenido en cuenta las tesis de doctorado de Emilia Cortés Ibáñez, José A. Bernardo de Quirós Mateo, Ángel Suárez Muñoz, M. del Mar López Cabrera, Agustina Torres Lara, Tomás Rubial Outes, Estefanía Fernández García y Eva Ocampo Vigo.

19 Publicada en microforma por la UNED en 2001

20 Publicada como La actividad escénica en Guadalajara entre 1920 y 1990 (Guadalajara, México: Universidad de Guadalajara, 2002 + 1 CD para la cartelera; con prólogo de José Romera Castillo).

${ }^{21}$ Parte de ella se ha publicado bajo el título de Teatro español en Italia: Valle-Inclán, García Lorca, Buero Vallejo, Sastre y Arrabal (Florencia: Alinea, 2003).

22 Publicada en microforma por la UNED en 1998 y posteriormente como Representaciones teatrales en Albacete 1901-1923. Cartelera, compañías y valoración (Albacete: Instituto de Estudios Albacetenses «Don Juan Manuel» de la Diputación Provincial, 1999; con prólogo de José Romera Castillo). Con reseña de Emilia Cortés Ibáñez, en Signa 10 (2001), 477-479 (también en http://cervantesvirtual.com/ hemeroteca/signa).

${ }^{23}$ Publicada en microforma por la UNED en 1998 y posteriormente como El teatro en Albacete durante la Edad de Plata (1924-1936) (Albacete: Instituto de Estudios Albacetenses «Don Juan Manuel» de la Diputación Provincial, 2000; con prólogo de José Romera Castillo).

${ }_{24}$ Publicada, primeramente, en microforma por la UNED en 1992 y posteriormente como El teatro en Alicante: 1901-1910. Cartelera y estudio (Madrid / Londres: Támesis / Generalitat Valenciana, 1994). Con reseña de Agustina Torres, en Signa 4 (1995), 261-264 (también puede leerse en http://cervantes virtual.com/hemeroteca/signa).

25 Publicada como Llanes. Teatro y Variedades 1923-1938 (Llanes: El Oriente de Asturias, 2004; con prólogo de Francisco Gutiérrez Carbajo). 
Roca, El teatro en Segovia (1918-1936) (2004) ${ }^{26}$ y María Ángel Somalo Fernández, El teatro en Logroño (1901-1950) (2004).

Aparecen, asimismo, en la página del Centro otras tesis de doctorado de Marina Sanfilippo, El renacimiento de la narración oral en Italia y España (1985-2005) (2006) 27; Santiago Trancón Pérez, Texto y representación: aproximación a una teoría crítica del teatro $(2004)^{28}$; M. ${ }^{a}$ del Pilar Regidor Nieto, Textos teatrales de Sergi Belbel, Joseph M. ${ }^{a}$ Benet $i$ Jornet, Ignacio del Moral y Jordi Sánchez y sus adaptaciones cinematográficas (1995-2000) (2004) y Sonia Sánchez Martínez, Aspectos semiológicos en la dramaturgia de Paloma Pedrero $(2005)^{29}$.

\section{OTROS ESTUDIOS}

Como colofón, señalaré algunos estudios relacionados con el tema que considero de interés. En las recopilaciones antológicas, editadas por María José Vega (2003), Literatura hipertextual y teoría literaria, se publica el trabajo de Gonzalo Pontón, «El hiperdrama. Alegoría escénica en la era digital» (150-159); así como el de Emilio Blanco, «Entre lo uno y lo perverso. Teatro, teatro digital y ciberteatro» (411-432), en María José Vega (ed., 2004), Poética y teatro. La teoría dramática del Renacimiento a la Posmodernidad.

En la recopilación de Domingo Sánchez-Mesa (2004), Literatura y cibercultura, aparece solamente un trabajo, traducido, relacionado en el tema: el de Matthew Causey, «La performance post-orgánica. La apariencia del teatro en los espacios virtuales» (297-325).

Anxo Abuín González (2006), por su parte, en Escenarios del caos. Entre la hipertextualidad y la 'performance' en la era electrónica (2006), un volumen muy heterogéneo, aunque de interés, inserta algunos microfragmentos relacionados con la teatralidad y las nuevas tecnologías ${ }^{30}$. Algo semejante podría decirse del volumen de Óscar Cornago (2005), Resistir en la era de los medios. Estrategias preformativas en literatura, teatro, cine y televisión.

\footnotetext{
${ }^{26}$ Publicada parte de ella (Madrid: Fundación Universitaria Española, 2005; con prólogo de José Romera Castillo).

27 Madrid: Fundación Universitaria Española 2007 (con prólogo de José Romera Castillo).

${ }_{28}$ Publicada como Teoría del teatro (Madrid: Fundamentos, 2006; con prólogo de Francisco Gutiérrez Carbajo).

29 Otras tesis de doctorado están en proceso de digitalización.

30 Como, por ejemplo, «Drama hipertextual» (85-87), «Drama interactivo» (89-91), etc.
} 
En Canadá, en la Université de Québec à Trois-Rivière, se ha creado un portal, Teatro de los Siglos de Oro (http://uqtr.calteatro/entrada/t.html), bajo la dirección de los españoles Ricardo Serrano Deza (2001) y Alfredo Hermenegildo, en el que, además de una revista - a la que me referiré después-, se presenta un Seminario Informática de texto (en proceso de revisión, en abril de 2007), el «Analizador Brocense» (analizador léxico de textos áureos), el «Banco textual de teatro áureo» (banco de textos teatrales áureos preparados para el análisis infoasistido: formatos BS y XML, en proceso de implantación), el «Asiento bibliográfico Radix» (Logicial de bibliografía para el teatro áureo) y «Otros contenidos» (crítica, congresos, enlaces, etc.).

La revista de la Asociación de Autores de Teatro, Las Puertas del Drama, editada en formato impreso y en Internet (http://www.aat.es/aat.html), ha dedicado alguna atención a nuestro tema. Por ejemplo, el dramaturgo Ignacio Amestoy (2000), que ha llevado a cabo alguna experiencia dramatúrgica digital (mama.com), reflexionaba sobre «Teatro, tiempo y ciberespacio» (9-11), inclinándose a que lo teatral debía entrar en lo que llamaba «infierno de las redes»; así como en el número 27 (2006), aparecen dos trabajos sobre el tema: el de José Antonio Pérez Bowie, «Escritura teatral y nuevas tecnologías» (4-7), centrado fundamentalmente en los efectos de las mismas en la escritura dramática; y el de José García Templado, «El teatro y las nuevas tecnologías: cohabitación o contaminatio» (24-27), que, pese al título, poco o nada tiene que ver con nuestro tema.

Sobre revistas en formato electrónico, además de la revista Signa - publicada en formato impreso y electrónico (http://cervantesvirtual.es/hemeroteca/signa) - , remito al trabajo de Manuel Pérez Jiménez (en Romera Castillo, ed., 2004), «Panorama de las publicaciones periódicas de investigación teatral desde 1990» (103-121), donde aparecen una serie de direcciones electrónicas de las mismas. Añadiré que, recientemente, la universidad canadiense de Québec à Trois-Rivière, en su portal de Teatro de los Siglos de Oro, anteriormente citado, se ha iniciado la publicación, con periodicidad anual, del número 1 (2007) de Teatro de palabras. Revista sobre teatro áureo (http://www.uqtr.ca/teatro/teapal/pal.html).

La revista de la Federación Latinoamericana de Semiótica, a la que pertenece la Asociación Española de Semiótica y de la que fui socio fundador, ha dedicado un número monográfico, Medios audiovisuales entre arte y tecnología, DeSignis 10 (2006), coordinado por Winfried Nöth, con la colaboración de los españoles José María Paz Gago y Eduardo Peñuela (residente 
en Brasil, donde ejerce la docencia en la Universidad de São Paulo), en el que el profesor de la Universidad de A Coruña, Paz Gago (2006) ha reflexionado, una vez más, sobre «Artes del espectáculo y nuevas tecnologías» (27-38).

Asimismo, hay informaciones colaterales sobre el teatro y las nuevas tecnologías en las guías bibliográficas sobre la relación de la literatura con estas herramientas, poniendo como ejemplo, entre otras, las de José Manuel Lucía Megías (2002), Literatura Románica en Internet. Los textos - en donde, tras una aclaratoria «Introducción», se dedican varios capítulos a «Los primeros pasos en Internet», «Bases de datos textuales», «Bibliotecas telemáticas» y «Los textos» (que van desde los orígenes, la épica, la lírica, la ficción extensa, la ficción breve, la literatura alegórica y didáctica, la literatura religiosa y hagiográfica, el teatro hasta la historiografía), más unos útiles índices (de autores, obras, investigadores y centros de investigación y primeros versos) - y José M. Lucía Megías y Aurelio Vargas Díaz-Toledo (2006), Literatura Románica en Internet. Las herramientas - que contiene información sobre «Las fuentes primarias: catálogos», «Las fuentes secundarias: bibliografías», «Enciclopedias, «Obras lexicográficas», «Revistas electrónicas», «Asociaciones científicas y listas de discusión», «Exposiciones virtuales» $\mathrm{y}$ «Temas afines»; más los índices (alfabético de sitios, completo, autores, obras, investigadores y centros de investigación)-. O la de Victoria Keating (1998), Literatura en Internet, en la que se ofrece una serie de direcciones en la red, clasificadas temáticamente, que van desde la poesía lírica, la poesía del siglo Xx, la epopeya y la poesía épica, la novela, el teatro, hasta los premios literarios, las editoriales, las publicaciones en castellano e inglés, los museos, organizaciones y fundaciones.

Pero de todo ello hay una mayor pormenorización en los trabajos de esta parte monográfica de la revista Signa, a cuya coordinadora y autores, como director de la misma, agradezco profundamente su colaboración.

\section{REFERENCIAS BIBLIOGRÁFICAS}

Abuín GonZÁLEZ, Anxo (2006). Escenarios del caos. Entre la hipertextualidad y la 'performance' en la era electrónica. Valencia: Tirant lo Blanch.

CORNAGO, Óscar (2005). Resistir en la era de los medios. Estrategias performativas en literatura, teatro, cine y televisión. Madrid / Frankfurt: Iberoamericana / Vervuet. 
KeAting, Victoria (1998). Literatura en Internet. Madrid: Ediciones Anaya Multimedia.

Lucía Mejías, José Manuel (2002). Literatura Románica en Internet. Los textos. Madrid: Castalia.

Lucía Mejías, José Manuel y Vargas Díaz-Toledo, Aurelio (2006). Literatura Románica en Internet. Las herramientas. Madrid: Castalia.

Revista DeSignis (2006). Medios audiovisuales entre arte y tecnología, 10 (Número monográfico, coordinado por Winfried Nöth, con la colaboración de los españoles José María Paz Gago y Eduardo Peñuela).

Romera Castillo, José (2004). «El teatro contemporáneo en la revista Signa dentro de las actividades del SELITEN@T». En Teatro, prensa y nuevas tecnologías (1990-2003), José Romera Castillo (ed.), 123-141. Madrid: Visor Libros.

- (2006). «Sobre teatro, prensa y nuevas tecnologías». En Literatura y periodismo. Estudios de Literatura Española Contemporánea, Fidel López Criado (ed.), 323-336. A Coruña: Artabria (Grupo de Investigación de la Universidad de A Coruña) / Diputación Provincial.

Romera CASTILlo, José et alii (eds.) (1997). Literatura y multimedia. Madrid: Visor Libros.

Romera CASTILlo, José (ed.) (2004). Teatro, prensa y nuevas tecnologías (1990-2003). Madrid: Visor Libros.

- (2006). Tendencias escénicas al inicio del siglo XXI. Madrid: Visor Libros.

SÁnCHEZ-MesA, Domingo (ed.) (2004). Literatura y cibercultura. Madrid: Arco / Libros.

SERrano Deza, Ricardo (2001). Manual de análisis infoasistido de textos aplicado al teatro de los Siglos de Oro. Madrid: UNED (Con «Presentación» de José Romera Castillo).

Vega, María José (ed.) (2003). Literatura hipertextual y teoría literaria. Madrid: Marenostrum.

- (2004). Poética y teatro. La teoría dramática del Renacimiento a la Posmodernidad. Vilagarcía de Arousa, Pontevedra: Mirabel. 